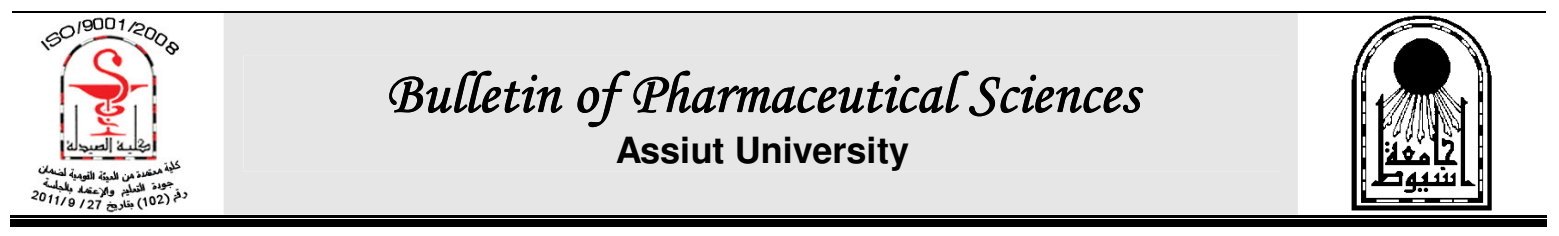

\title{
SYNTHESIS AND BIOLOGICAL EVALUATION OF SOME NEW COUMARIN DERIVATIVES AS ANTIMICROBIAL AGENTS
}

\author{
Bahaa Gamal Mohamed Youssif* \\ Department of Pharmaceutical Organic Chemistry, Faculty of Pharmacy, Assiut University, \\ Assiut 71526, Egypt
}

A series of new 7-[2-(3-alkyl/aryl-4-arylthiazol-2(3H)-ylidene)hydrazono)propoxy]-4methyl-2H-chromen-2-ones, (6-9a-e), was prepared by the reaction of appropriate $\mathrm{N}$-alkyl/aryl2-[1-(4-methyl-2-oxo-2H-chromen-7yloxy)propan-2-ylidene] hydrazine carbothioamides (4a-d) and phenacyl bromides (5a-e). The purity of all new compounds was checked by TLC and elucidation of their structures was confirmed by $I R,{ }^{1} H$ NMR, and mass spectrometry along with elemental microanalyses. All the target compounds were evaluated for their possible antimicrobial activity. Most of the tested compounds showed weak to moderate antibacterial activity against most of the bacterial strains used in comparison with gatifloxacin as a reference drug. The most active compounds were $\mathbf{6} \boldsymbol{b}, \boldsymbol{6} \boldsymbol{c}, \mathbf{7 b}, \mathbf{8 b}, \mathbf{8 c}$, and $9 \boldsymbol{c}$ against $B$. cereus, E. coli and $S$. marcescens. Results of antifungal activity revealed that all compounds showed weak to moderate activity against $S$. brevicaulis, while ketoconazole as a reference drug was completely inactive. Compounds $\boldsymbol{6} \boldsymbol{a}, \boldsymbol{6} \boldsymbol{b}, \boldsymbol{6} \boldsymbol{c}, \boldsymbol{6} \boldsymbol{e}$ and $7 \boldsymbol{b}$ were even more active than ketoconazole against $F$. oxysporum.

\section{INTRODUCTION}

Coumarins (2H-1-benzopyran-2-ones) are important oxygen containing fused heterocycles used in drugs and dyes ${ }^{1}$. They are the family of lactones containing benzopyrone skeletal framework that have enjoyed isolation from plant as well as total synthesis in the laboratory $^{2}$. The incorporation of other heterocyclic moiety either as substituent group or as a fused component into the parent coumarin alters the property of parent coumarin and converts it into a more useful product $^{3}$. Coumarins are plant flavonoids widely distributed in nature. Natural coumarins are known to have antidiabetic activity ${ }^{4}$, anabolic, antioxidant and hepato protective activities $^{5 \& 6}$. Substituted coumarin derivatives have been reported to have variety of biological activities including anticoagulant ${ }^{7}$, HIV protease inhibition ${ }^{8}$, CNS depressant ${ }^{9}$, analgesic $^{10}$ and anti-tubercular activities ${ }^{11}$. The potent antibiotics like novobiocin ${ }^{12}$, coumarmycin $^{13}$ and chlorobiocin ${ }^{14}$ are coumarin derivatives. Recently, the interest on these compounds has been reviewed owing to their use as fluorescent markers in the biochemical determination of enzymes ${ }^{15}$.

On the other hand, literature survey revealed that thiosemicarbazones constitute one of the most versatile classes of compounds possessing antimicrobial and anti-amoebic activities $^{16-20}$, depending on the nature of the substituents at $\mathrm{N}^{1}$ and $\mathrm{N}^{4}$ of thiosemicarbazone moiety. Various thiosemicarbazone derivatives have been successfully developed and documented as antimicrobial agents ${ }^{16-21}$.

Enlightened by the aforementioned studies, the present work aims at the synthesis of some new thiazoline coumarin compounds (6-9a-e) derived by cyclization of coumarin thiosemicarbazones (4a-d) to be subjected for preliminary in-vitro screening of their antibacterial and antifungal activities using the agar disc diffusion method.

Received in 6/8/2013 \& Accepted in 28/10/2013 


\section{MATERIALS AND METHODS}

Melting points were determined on an electro thermal melting point apparatus [Stuart Scientific, model SMP3, England, UK], and were uncorrected. A pre-coated silica gel plate (kieselgel $0.25 \mathrm{~mm}$, 60G F254, Merck, Germany) was used for TLC monitoring of reactions. The developing solvent system $n$ Hexane/ethylacetate $(3: 2 \mathrm{v} / \mathrm{v})$ was used and the spots were detected at $254 \mathrm{~nm}$ wavelength using ultraviolet lamp (Spectroline, model CM10, USA). IR spectra ( $\mathrm{KBr}$ discs) were recorded on a shimadzu IR-470 spectrometer (Shimadzu, Kyoto, Japan) at Faculty of Pharmacy, Assiut University, Assiut. ${ }^{1} \mathrm{H}$ NMR Spectra were scanned on a Varian EM-360 L NMR spectrometer $(60 \mathrm{MHz}$, Varian, CA, USA) at Faculty of Pharmacy, Assiut University, Assiut. Chemical shifts are expressed in $\delta$-value ( $\mathrm{ppm}$ ) relative to TMS as an internal standard, using DMSO- $\mathrm{d}_{6}$, unless otherwise specified, as a solvent, and deuterium oxide was used for the detection of exchangeable protons. Mass spectra were recorded with JEOL JMS600 mass spectrometer (JEOL, Tokyo, Japan), Assiut University Central Lab, Assiut and at the unit of Microanalysis, Faculty of Science, Cairo University, Cairo. Elemental microanalyses were performed on a Perkin-Elmer 240 elemental analyzer (Perkin-Elmer, USA) at the unit of Microanalysis, Faculty of Science, Cairo University, Cairo. Reagents used for synthesis were purchased from Sigma-Aldrich (Gillingham - Dorest, UK) and MERCK (Schuchardt, Germany). All solvents were obtained from commercial suppliers and used without further purification.

The starting materials 7-hydroxy-4methyl-2H-chromen-2-one (1) ${ }^{22}$, 4-methyl-7-(2oxopropoxy)- $2 H$-chromen-2-one $\quad(2)^{23} \quad 4$ substituted-3-thiosemicarbazides (3a-d) ${ }^{24}$, and phenacyl bromides $(\mathbf{5 a - e})^{25}$; were synthesized according to reported procedures.

\section{Chemistry}

Synthesis of $N$-alkyl/aryl-2-[1-(4-methyl-2oxo-2H-chromen-7-yloxy)propan-2-ylidene] hydrazine carbothioamides (4a-d)

To an equimolar amount of the appropriate 4-substituted-3-thiosemicarbazide (3a-d) $(5.3 \mathrm{mmol})$ in absolute ethanol $(50 \mathrm{~mL})$, 4-methyl-7-(2-oxopropoxy)-2H-chromen-2-one (2) $(5.3 \mathrm{mmol})$ was added. The mixture was refluxed for 4-6 hrs in the presence of 1-2 drops of glacial acetic acid. The formed precipitate of compounds $\mathrm{N}$-alkyl/aryl-2-[1-(4methyl-2-oxo-2H-chromen-7-yloxy)propan-2ylidene]hydrazine carbothioamides (4a-d) was filtered, dried and crystallized from ethanol to afford pure compounds. Yields, m.p., elemental analyses, IR, ${ }^{1} \mathrm{H}$ NMR and mass spectral data are listed in tables 1 and 2.

Synthesis of 7-[2-(3-alkyl/aryl-4-arylthiazol2(3H)-ylidene)hydrazono)propoxy]-4methyl-2H-chromen-2-ones (6-9a-e)

A solution of the appropriate thiosemicarbazone derivative (4a-d) (1.5 mmol) in absolute ethanol $(30 \mathrm{~mL})$ and the appropriate phenacyl bromide (5a-e) (1.5 mmol) was heated under reflux for 6-8 hrs in the presence of anhydrous sodium acetate (100 $\mathrm{mg}$ ). Following up of the reaction was done by TLC. The reaction mixture was concentrated and poured onto ice cold water for complete separation of the product which was filtered, dried and crystallized from ethanol to afford pure compounds 6-9a-e. Yields, m.p., elemental analyses, IR, ${ }^{1} \mathrm{H}$ NMR and mass spectral data are listed in tables 1 and 2.

\section{Antimicrobial screening}

\section{a) Antibacterial activity}

\section{Organisms and culture conditions}

The used bacterial cultures were obtained from Assiut University Mycological Center (AUMC), Assiut University, Assiut. The antibacterial activity of compounds 4a-d and 69a-e was determined according to the agar disc diffusion method ${ }^{26}$.

Six bacterial species were used to test the antibacterial activity of the target compounds: Bacillus cereus (AUMC B70), Staphylococcus aureus (AUMC B71) and Micrococcus luteus (AUMC B68) as representatives of Gram positive strains, while the Gram negative strains were represented by Escherichia coli (AUMC B69), Pseudomonas aeruginosa (AUMC B72) and Serratia marcescens (AUMC B67). 
Table 1: Physicochemical properties of compounds 4a-d and 6-9a-e.

\begin{tabular}{|c|c|c|c|c|c|c|c|c|}
\hline \multirow{2}{*}{$\begin{array}{l}\text { Compd. } \\
\text { No. }\end{array}$} & \multirow[t]{2}{*}{$\mathrm{R}$} & \multirow[t]{2}{*}{$\mathrm{R}^{1}$} & \multirow{2}{*}{$\begin{array}{l}\text { Yield } \\
(\%)\end{array}$} & \multirow{2}{*}{$\begin{array}{l}\text { M.p. } \\
\left({ }^{\circ} \mathrm{C}\right)\end{array}$} & \multirow{2}{*}{$\begin{array}{c}\text { M.F. } \\
\text { (M.Wt.) }\end{array}$} & \multicolumn{3}{|c|}{$\begin{array}{c}\text { Microanalysis } \\
\text { (calculated/found) }\end{array}$} \\
\hline & & & & & & $\mathrm{C} \%$ & $\mathrm{H} \%$ & $\mathrm{~N} \%$ \\
\hline $4 a$ & $\mathrm{C}_{2} \mathrm{H}_{5}$ & -- & 82 & $163-165$ & $\begin{array}{c}\mathrm{C}_{16} \mathrm{H}_{19} \mathrm{~N}_{3} \mathrm{O}_{3} \mathrm{~S} \\
(333.11)\end{array}$ & $\begin{array}{l}57.64 \\
57.60\end{array}$ & $\begin{array}{l}5.74 \\
5.68\end{array}$ & $\begin{array}{l}12.60 \\
12.66\end{array}$ \\
\hline $4 b$ & $\mathrm{CH}\left(\mathrm{CH}_{3}\right)_{2}$ & -- & 81 & $142-144$ & $\begin{array}{c}\mathrm{C}_{17} \mathrm{H}_{21} \mathrm{~N}_{3} \mathrm{O}_{3} \mathrm{~S} \\
(347.13)\end{array}$ & $\begin{array}{l}58.77 \\
58.81\end{array}$ & $\begin{array}{l}6.09 \\
6.12 \\
\end{array}$ & $\begin{array}{l}12.09 \\
12.05 \\
\end{array}$ \\
\hline $4 c$ & $\mathrm{C}_{6} \mathrm{H}_{5}$ & -- & 76 & $185-187$ & $\begin{array}{c}\mathrm{C}_{20} \mathrm{H}_{19} \mathrm{~N}_{3} \mathrm{O}_{3} \mathrm{~S} \\
(381.11)\end{array}$ & $\begin{array}{l}62.97 \\
62.90\end{array}$ & $\begin{array}{l}5.02 \\
5.42\end{array}$ & $\begin{array}{l}11.02 \\
10.97\end{array}$ \\
\hline $4 d$ & $p$-tolyl & -- & 74 & $213-215$ & $\begin{array}{c}\mathrm{C}_{21} \mathrm{H}_{21} \mathrm{~N}_{3} \mathrm{O}_{3} \mathrm{~S} \\
(395.13)\end{array}$ & $\begin{array}{l}63.78 \\
63.79\end{array}$ & $\begin{array}{l}5.35 \\
5.29\end{array}$ & $\begin{array}{l}10.63 \\
10.58\end{array}$ \\
\hline $6 a$ & $\mathrm{C}_{2} \mathrm{H}_{5}$ & $\mathrm{H}$ & 89 & $176-178$ & $\begin{array}{c}\mathrm{C}_{24} \mathrm{H}_{23} \mathrm{~N}_{3} \mathrm{O}_{3} \mathrm{~S} \\
(433.15)\end{array}$ & $\begin{array}{l}66.49 \\
66.18\end{array}$ & $\begin{array}{l}5.35 \\
5.09\end{array}$ & $\begin{array}{l}9.69 \\
9.53\end{array}$ \\
\hline $6 b$ & $\mathrm{C}_{2} \mathrm{H}_{5}$ & $\mathrm{Br}$ & 81 & $205-207$ & $\begin{array}{c}\mathrm{C}_{24} \mathrm{H}_{22} \mathrm{BrN}_{3} \mathrm{O}_{3} \mathrm{~S} \\
(511.06)\end{array}$ & $\begin{array}{l}56.25 \\
55.93\end{array}$ & $\begin{array}{l}4.33 \\
4.09 \\
\end{array}$ & $\begin{array}{l}8.20 \\
8.53\end{array}$ \\
\hline $6 c$ & $\mathrm{C}_{2} \mathrm{H}_{5}$ & $\mathrm{Cl}$ & 72 & $201-203$ & $\begin{array}{c}\mathrm{C}_{24} \mathrm{H}_{22} \mathrm{ClN}_{3} \mathrm{O}_{3} \mathrm{~S} \\
(467.11)\end{array}$ & $\begin{array}{l}61.60 \\
61.03 \\
\end{array}$ & $\begin{array}{l}4.74 \\
4.90 \\
\end{array}$ & $\begin{array}{l}8.98 \\
8.89\end{array}$ \\
\hline 6d & $\mathrm{C}_{2} \mathrm{H}_{5}$ & $\mathrm{CH}_{3}$ & 84 & $204-206$ & $\begin{array}{c}\mathrm{C}_{25} \mathrm{H}_{25} \mathrm{~N}_{3} \mathrm{O}_{3} \mathrm{~S} \\
(447.16)\end{array}$ & $\begin{array}{l}67.09 \\
67.59\end{array}$ & $\begin{array}{l}5.63 \\
5.84\end{array}$ & $\begin{array}{l}9.39 \\
9.45\end{array}$ \\
\hline $6 e$ & $\mathrm{C}_{2} \mathrm{H}_{5}$ & $\mathrm{OCH}_{3}$ & 78 & $186-188$ & $\begin{array}{c}\mathrm{C}_{25} \mathrm{H}_{25} \mathrm{~N}_{3} \mathrm{O}_{4} \mathrm{~S} \\
(463.16)\end{array}$ & $\begin{array}{l}64.78 \\
64.34\end{array}$ & $\begin{array}{l}5.44 \\
5.55\end{array}$ & $\begin{array}{l}9.06 \\
8.84\end{array}$ \\
\hline $7 a$ & $\mathrm{CH}\left(\mathrm{CH}_{3}\right)_{2}$ & $\mathrm{H}$ & 70 & $146-148$ & $\begin{array}{c}\mathrm{C}_{25} \mathrm{H}_{25} \mathrm{~N}_{3} \mathrm{O}_{3} \mathrm{~S} \\
(447.16)\end{array}$ & $\begin{array}{l}67.09 \\
66.64\end{array}$ & $\begin{array}{l}5.63 \\
5.41\end{array}$ & $\begin{array}{l}9.39 \\
9.24\end{array}$ \\
\hline $7 b$ & $\mathrm{CH}\left(\mathrm{CH}_{3}\right)_{2}$ & $\mathrm{Br}$ & 80 & $170-172$ & $\begin{array}{r}\mathrm{C}_{25} \mathrm{H}_{24} \mathrm{Br} \\
(525.0\end{array}$ & $\begin{array}{l}57.04 \\
56.87\end{array}$ & $\begin{array}{l}4.60 \\
4.33\end{array}$ & $\begin{array}{l}7.98 \\
7.69\end{array}$ \\
\hline $7 c$ & $\mathrm{CH}\left(\mathrm{CH}_{3}\right)_{2}$ & $\mathrm{Cl}$ & 77 & $192-194$ & $\begin{array}{c}\mathrm{C}_{25} \mathrm{H}_{24} \mathrm{ClN}_{3} \mathrm{O}_{3} \mathrm{~S} \\
(481.12)\end{array}$ & $\begin{array}{l}62.30 \\
62.31\end{array}$ & $\begin{array}{l}5.02 \\
5.54\end{array}$ & $\begin{array}{l}8.72 \\
8.91\end{array}$ \\
\hline $7 d$ & $\mathrm{CH}\left(\mathrm{CH}_{3}\right)_{2}$ & $\mathrm{CH}_{3}$ & 72 & $164-166$ & $\begin{array}{c}\mathrm{C}_{26} \mathrm{H}_{27} \mathrm{~N}_{3} \mathrm{O}_{3} \mathrm{~S} \\
(461.18)\end{array}$ & $\begin{array}{l}67.65 \\
67.12\end{array}$ & $\begin{array}{l}5.90 \\
5.48\end{array}$ & $\begin{array}{l}9.10 \\
8.95\end{array}$ \\
\hline $7 e$ & $\mathrm{CH}\left(\mathrm{CH}_{3}\right)_{2}$ & $\mathrm{OCH}_{3}$ & 73 & $189-190$ & $\begin{array}{c}\mathrm{C}_{26} \mathrm{H}_{27} \mathrm{~N}_{3} \mathrm{O}_{4} \mathrm{~S} \\
(477.17)\end{array}$ & $\begin{array}{l}65.39 \\
64.98\end{array}$ & $\begin{array}{l}5.70 \\
5.32\end{array}$ & $\begin{array}{l}8.80 \\
8.67\end{array}$ \\
\hline $8 \mathbf{a}$ & $\mathrm{C}_{6} \mathrm{H}_{5}$ & $\mathrm{H}$ & 68 & 197-199 & $\begin{array}{c}\mathrm{C}_{28} \mathrm{H}_{23} \mathrm{~N}_{3} \mathrm{O}_{3} \mathrm{~S} \\
(481.15)\end{array}$ & $\begin{array}{l}69.83 \\
69.47\end{array}$ & $\begin{array}{l}4.81 \\
5.14\end{array}$ & $\begin{array}{l}8.73 \\
9.12\end{array}$ \\
\hline $8 b$ & $\mathrm{C}_{6} \mathrm{H}_{5}$ & $\mathrm{Br}$ & 63 & 204-206 & $\begin{array}{c}\mathrm{C}_{28} \mathrm{H}_{22} \mathrm{BrN}_{3} \mathrm{O}_{3} \mathrm{~S} \\
(559.06)\end{array}$ & $\begin{array}{l}60.00 \\
59.48\end{array}$ & $\begin{array}{l}3.96 \\
3.52 \\
\end{array}$ & $\begin{array}{l}7.50 \\
7.02\end{array}$ \\
\hline $8 c$ & $\mathrm{C}_{6} \mathrm{H}_{5}$ & $\mathrm{Cl}$ & 70 & $199-201$ & $\begin{array}{c}\mathrm{C}_{28} \mathrm{H}_{22} \mathrm{ClN}_{3} \mathrm{O}_{3} \mathrm{~S} \\
(515.11)\end{array}$ & $\begin{array}{l}65.17 \\
65.15\end{array}$ & $\begin{array}{l}4.30 \\
4.38\end{array}$ & $\begin{array}{l}8.14 \\
7.89\end{array}$ \\
\hline $8 d$ & $\mathrm{C}_{6} \mathrm{H}_{5}$ & $\mathrm{CH}_{3}$ & 89 & $210-212$ & $\begin{array}{c}\mathrm{C}_{29} \mathrm{H}_{25} \mathrm{~N}_{3} \mathrm{O}_{3} \mathrm{~S} \\
(495.16)\end{array}$ & $\begin{array}{l}70.28 \\
70.24\end{array}$ & $\begin{array}{l}5.08 \\
5.17\end{array}$ & $\begin{array}{l}8.48 \\
8.26\end{array}$ \\
\hline $8 e$ & $\mathrm{C}_{6} \mathrm{H}_{5}$ & $\mathrm{OCH}_{3}$ & 75 & $192-194$ & $\begin{array}{c}\mathrm{C}_{29} \mathrm{H}_{25} \mathrm{~N}_{3} \mathrm{O}_{4} \mathrm{~S} \\
(511.16)\end{array}$ & $\begin{array}{l}68.08 \\
67.85\end{array}$ & $\begin{array}{l}4.93 \\
5.30\end{array}$ & $\begin{array}{l}8.21 \\
7.86\end{array}$ \\
\hline $9 \mathbf{a}$ & $p$-tolyl & $\mathrm{H}$ & 74 & $136-138$ & $\begin{array}{c}\mathrm{C}_{29} \mathrm{H}_{25} \mathrm{~N}_{3} \mathrm{O}_{3} \mathrm{~S} \\
(495.16)\end{array}$ & $\begin{array}{l}70.28 \\
70.61 \\
\end{array}$ & $\begin{array}{l}5.08 \\
5.04 \\
\end{array}$ & $\begin{array}{l}8.48 \\
8.44 \\
\end{array}$ \\
\hline $9 \mathrm{~b}$ & $p$-tolyl & $\mathrm{Br}$ & 88 & $202-205$ & $\begin{array}{c}\mathrm{C}_{29} \mathrm{H}_{24} \mathrm{BrN}_{3} \mathrm{O}_{3} \mathrm{~S} \\
(573.07)\end{array}$ & $\begin{array}{l}60.63 \\
60.24 \\
\end{array}$ & $\begin{array}{l}4.21 \\
4.17 \\
\end{array}$ & $\begin{array}{l}7.31 \\
7.67 \\
\end{array}$ \\
\hline $9 c$ & $p$-tolyl & $\mathrm{Cl}$ & 81 & $212-214$ & $\begin{array}{c}\mathrm{C}_{29} \mathrm{H}_{24} \mathrm{ClN}_{3} \mathrm{O}_{3} \mathrm{~S} \\
(529.12)\end{array}$ & $\begin{array}{l}65.71 \\
65.43\end{array}$ & $\begin{array}{l}4.56 \\
4.25\end{array}$ & $\begin{array}{l}7.93 \\
7.48\end{array}$ \\
\hline 9d & $p$-tolyl & $\mathrm{CH}_{3}$ & 70 & 196-198 & $\begin{array}{c}\mathrm{C}_{30} \mathrm{H}_{27} \mathrm{~N}_{3} \mathrm{O}_{3} \mathrm{~S} \\
(509.18)\end{array}$ & $\begin{array}{l}70.70 \\
70.46\end{array}$ & $\begin{array}{l}5.34 \\
5.03\end{array}$ & $\begin{array}{l}8.25 \\
8.15\end{array}$ \\
\hline $9 e$ & $p$-tolyl & $\mathrm{OCH}_{3}$ & 64 & 193-195 & $\begin{array}{c}\mathrm{C}_{30} \mathrm{H}_{27} \mathrm{~N}_{3} \mathrm{O}_{4} \mathrm{~S} \\
(525.17)\end{array}$ & $\begin{array}{l}68.55 \\
68.41\end{array}$ & $\begin{array}{l}5.18 \\
4.99\end{array}$ & $\begin{array}{l}7.99 \\
7.87\end{array}$ \\
\hline
\end{tabular}


Table 2: Spectral characterization of compounds 4a-d and 6-9a-e.

\begin{tabular}{|c|c|c|c|}
\hline $\begin{array}{l}\text { Compd. } \\
\text { No. }\end{array}$ & $\begin{array}{l}\mathrm{IR}(\mathrm{KBr}) \\
\left(\hat{v}, \mathrm{~cm}^{-1}\right) \\
\end{array}$ & ${ }^{1} \mathrm{H}$ NMR $\left(\mathrm{DMSO}-\mathrm{d}_{6}, \delta \mathrm{ppm}\right)$ & $\begin{array}{c}\text { MS } \\
(\mathrm{m} / \mathrm{z})\end{array}$ \\
\hline $4 \mathbf{a}$ & $\begin{array}{lr}3390, & 3350 \\
(\mathrm{NH}), & 1622 \\
(\mathrm{C}=\mathrm{N}), & 1579 \\
(\mathrm{Ar}-\mathrm{C}=\mathrm{C}) & \end{array}$ & $\begin{array}{l}0.9-1.3\left(\mathrm{t}, 3 \mathrm{H}, \mathrm{CH}_{2} \mathrm{CH}_{3}\right), 2-2.6\left(\mathrm{~m}, 8 \mathrm{H}, \mathrm{CH}_{3} \mathrm{CH}_{2}, \mathrm{NCCH}_{3} \text {, and }\right. \\
\left.\text { coumarin- } \mathrm{CH}_{3}\right), 5\left(\mathrm{~s}, 2 \mathrm{H}, \mathrm{OCH}_{2}\right), 6.3\left(\mathrm{~s}, 1 \mathrm{H}, \mathrm{C}-\mathrm{H}_{3} \text { of coumarin }\right), \\
6.8-7.3(\mathrm{~m}, 2 \mathrm{H}, \mathrm{Ar}-\mathrm{H}), 7.4-7.6(\mathrm{~d}, 1 \mathrm{H}, \mathrm{Ar}-\mathrm{H}), 9.2\left(\mathrm{~s}, 1 \mathrm{H}, \mathrm{NH}, \mathrm{D}_{2} \mathrm{O}\right. \\
\text { exchangeable }), 10.4\left(\mathrm{~s}, 1 \mathrm{H}, \mathrm{NH}, \mathrm{D}_{2} \mathrm{O} \text { exchangeable }\right) .\end{array}$ & $\begin{array}{l}334.12 \\
\left(\mathrm{M}^{+}+1\right)\end{array}$ \\
\hline $4 b$ & $\begin{array}{lr}3381, & 3350 \\
(\mathrm{NH}), & 1625 \\
(\mathrm{C}=\mathrm{N}), & 1580 \\
(\mathrm{Ar}-\mathrm{C}=\mathrm{C})\end{array}$ & $\begin{array}{l}\text { 1.1-1.3 }\left(\mathrm{d}, 6 \mathrm{H}, \mathrm{CH}\left(\mathrm{CH}_{3}\right)_{2}\right), 2.2\left(\mathrm{~s}, 3 \mathrm{H}, \mathrm{NCCH}_{3}\right), 2.5(\mathrm{~s}, 3 \mathrm{H}, \\
\left.\text { coumarin- } \mathrm{CH}_{3}\right), 3.1-3.3\left(\mathrm{~m}, 1 \mathrm{H}, \mathrm{CH}\left(\mathrm{CH}_{3}\right)_{2}\right), 4.8\left(\mathrm{~s}, 2 \mathrm{H}, \mathrm{OCH}_{2}\right), \\
6.4\left(\mathrm{~s}, 1 \mathrm{H}, \mathrm{C}-\mathrm{H}_{3} \text { of coumarin }\right), 6.8-7.2(\mathrm{~m}, 2 \mathrm{H}, \mathrm{Ar}-\mathrm{H}), 7.4-7.6(\mathrm{~d}, \\
1 \mathrm{H}, \text { Ar-H }), 8.9\left(\mathrm{~s}, 1 \mathrm{H}, \mathrm{NH}, \mathrm{D}_{2} \mathrm{O} \text { exchangeable }\right), 10.8(\mathrm{~s}, 1 \mathrm{H}, \mathrm{NH}, \\
\mathrm{D}_{2} \mathrm{O} \text { exchangeable). }\end{array}$ & $\begin{array}{l}348.13 \\
\left(\mathrm{M}^{+}+1\right)\end{array}$ \\
\hline $4 c$ & $\begin{array}{ll}3385, & 3351 \\
(\mathrm{NH}), & 1622 \\
(\mathrm{C}=\mathrm{N}), & 1589, \\
(\mathrm{Ar}-\mathrm{C}=\mathrm{C})\end{array}$ & $\begin{array}{l}2.2\left(\mathrm{~s}, 3 \mathrm{H}, \mathrm{NCCH}_{3}\right), 2.4\left(\mathrm{~s}, 3 \mathrm{H}, \text { coumarin- } \mathrm{CH}_{3}\right), 4.9(\mathrm{~s}, 2 \mathrm{H}, \\
\left.\mathrm{OCH}_{2}\right), 6.2\left(\mathrm{~s}, 1 \mathrm{H}, \mathrm{C}-\mathrm{H}_{3} \text { of coumarin }\right), 6.9-7.8(\mathrm{~m}, 8 \mathrm{H}, \mathrm{Ar}-\mathrm{H}), 9.6 \\
\left(\mathrm{~s}, 1 \mathrm{H}, \mathrm{NH}, \mathrm{D}_{2} \mathrm{O} \text { exchangeable }\right), 10.3\left(\mathrm{~s}, 1 \mathrm{H}, \mathrm{NH}, \mathrm{D}_{2} \mathrm{O}\right. \\
\text { exchangeable })\end{array}$ & $\begin{array}{l}382.12 \\
\left(\mathrm{M}^{+}+1\right)\end{array}$ \\
\hline $4 d$ & $\begin{array}{lr}3390, & 3348 \\
(\mathrm{NH}), & 1620 \\
(\mathrm{C}=\mathrm{N}), & 1598 \\
(\mathrm{Ar}-\mathrm{C}=\mathrm{C})\end{array}$ & $\begin{array}{l}2.1\left(\mathrm{~s}, 3 \mathrm{H}, \mathrm{Ar}-\mathrm{CH}_{3}\right), 2.3-2.5\left(\mathrm{~m}, 6 \mathrm{H}, \mathrm{NCCH}_{3} \text {, and coumarin- } \mathrm{CH}_{3}\right), \\
4.8\left(\mathrm{~s}, 2 \mathrm{H}, \mathrm{OCH}_{2}\right), 6.2\left(\mathrm{~s}, 1 \mathrm{H}, \mathrm{C}-\mathrm{H}_{3} \text { of coumarin }\right), 6.9-7.7(\mathrm{~m}, 7 \mathrm{H}, \\
\mathrm{Ar}-\mathrm{H}), 9.6\left(\mathrm{~s}, 1 \mathrm{H}, \mathrm{NH}, \mathrm{D}_{2} \mathrm{O} \text { exchangeable }\right), 10.5\left(\mathrm{~s}, 1 \mathrm{H}, \mathrm{NH}, \mathrm{D}_{2} \mathrm{O}\right. \\
\text { exchangeable }) .\end{array}$ & $\begin{array}{l}396.13 \\
\left(\mathrm{M}^{+}+1\right)\end{array}$ \\
\hline $6 \mathbf{a}$ & $\begin{array}{l}1562(\mathrm{C}=\mathrm{N}) \\
1528,1491 \\
(\mathrm{C}=\mathrm{C}), 1248 \\
1171(\mathrm{C}-\mathrm{S}-\mathrm{C}) \\
\end{array}$ & $\begin{array}{l}1.1-1.3\left(\mathrm{t}, 3 \mathrm{H}, \mathrm{CH}_{2} \mathrm{CH}_{3}\right), 2.3\left(\mathrm{~s}, 3 \mathrm{H}, \mathrm{NCCH}_{3}\right), 2.7(\mathrm{~s}, 3 \mathrm{H}, \\
\left.\text { coumarin- } \mathrm{CH}_{3}\right), 3.9-4.4\left(\mathrm{q}, 2 \mathrm{H}, \mathrm{CH}_{2} \mathrm{CH}_{3}\right), 5.1\left(\mathrm{~s}, 2 \mathrm{H}, \mathrm{OCH}_{2}\right), 6.3 \\
\left(\mathrm{~s}, 1 \mathrm{H}, \mathrm{C}-\mathrm{H}_{3} \text { of coumarin }\right), 6.6(\mathrm{~s}, 1 \mathrm{H}, \mathrm{CH} \text { of thiazoline }), 6.95-7.8 \\
(\mathrm{~m}, 8 \mathrm{H}, \mathrm{Ar}-\mathrm{H}) .\end{array}$ & $\begin{array}{l}434.15 \\
\left(\mathrm{M}^{+}+1\right)\end{array}$ \\
\hline $6 \mathbf{b}$ & $\begin{array}{l}1572(\mathrm{C}=\mathrm{N}) \\
1525,1491 \\
(\mathrm{C}=\mathrm{C}), 1248 \\
1171(\mathrm{C}-\mathrm{S}-\mathrm{C})\end{array}$ & $\begin{array}{l}1.2-1.35\left(\mathrm{t}, 3 \mathrm{H}, \mathrm{CH}_{2} \mathrm{CH}_{3}\right), 2.3\left(\mathrm{~s}, 3 \mathrm{H}, \mathrm{NCCH}_{3}\right), 2.8(\mathrm{~s}, 3 \mathrm{H}, \\
\left.\text { coumarin- } \mathrm{CH}_{3}\right), 3.8-4.2\left(\mathrm{q}, 2 \mathrm{H}, \mathrm{CH}_{2} \mathrm{CH}_{3}\right), 5.1\left(\mathrm{~s}, 2 \mathrm{H}, \mathrm{OCH}_{2}\right), 6.3 \\
\left(\mathrm{~s}, 1 \mathrm{H}, \mathrm{C}-\mathrm{H}_{3} \text { of coumarin }\right), 6.7(\mathrm{~s}, 1 \mathrm{H}, \mathrm{CH} \text { of thiazoline }), 6.9-7.8 \\
(\mathrm{~m}, 7 \mathrm{H}, \mathrm{Ar}-\mathrm{H}) .\end{array}$ & $\begin{array}{l}512.06 \\
\left(\mathrm{M}^{+}+1\right)\end{array}$ \\
\hline $6 c$ & $\begin{array}{l}1562(\mathrm{C}=\mathrm{N}) \\
1518,1471 \\
(\mathrm{C}=\mathrm{C}), 1248 \\
1176(\mathrm{C}-\mathrm{S}-\mathrm{C})\end{array}$ & $\begin{array}{l}1.1-1.4\left(\mathrm{t}, 3 \mathrm{H}, \mathrm{CH}_{2} \mathrm{CH}_{3}\right), 2.3\left(\mathrm{~s}, 3 \mathrm{H}, \mathrm{NCCH}_{3}\right), 2.8(\mathrm{~s}, 3 \mathrm{H}, \\
\left.\text { coumarin- } \mathrm{CH}_{3}\right), 3.7-4.1\left(\mathrm{q}, 2 \mathrm{H}, \mathrm{CH}_{2} \mathrm{CH}_{3}\right), 5.1\left(\mathrm{~s}, 2 \mathrm{H}, \mathrm{OCH}_{2}\right), 6.3 \\
\left(\mathrm{~s}, 1 \mathrm{H}, \mathrm{C}-\mathrm{H}_{3} \text { of coumarin }\right), 6.6(\mathrm{~s}, 1 \mathrm{H}, \mathrm{CH} \text { of thiazoline }), 6.9-7.8 \\
(\mathrm{~m}, 7 \mathrm{H}, \mathrm{Ar}-\mathrm{H}) .\end{array}$ & $\begin{array}{c}468.11 \\
\left(\mathrm{M}^{+}+1\right)\end{array}$ \\
\hline $6 d$ & $\begin{array}{l}1573(\mathrm{C}=\mathrm{N}) \\
1518,1480 \\
(\mathrm{C}=\mathrm{C}), 1248 \\
1178(\mathrm{C}-\mathrm{S}-\mathrm{C}) \\
\end{array}$ & $\begin{array}{l}1.1-1.4\left(\mathrm{t}, 3 \mathrm{H}, \mathrm{CH}_{2} \mathrm{CH}_{3}\right), 2.4\left(\mathrm{~s}, 3 \mathrm{H}, \mathrm{NCCH}_{3}\right), 2.6\left(\mathrm{~s}, 6 \mathrm{H}, \mathrm{Ar}-\mathrm{CH}_{3}\right. \\
\left.\text { and coumarin- } \mathrm{CH}_{3}\right), 3.7-4.1\left(\mathrm{q}, 2 \mathrm{H}, \mathrm{CH}_{2} \mathrm{CH}_{3}\right), 5.1\left(\mathrm{~s}, 2 \mathrm{H}, \mathrm{OCH}_{2}\right), \\
6.3\left(\mathrm{~s}, 1 \mathrm{H}, \mathrm{C}-\mathrm{H}_{3} \text { of coumarin }\right), 6.6(\mathrm{~s}, 1 \mathrm{H}, \mathrm{CH} \text { of thiazoline }), 6.8- \\
7.8(\mathrm{~m}, 7 \mathrm{H}, \mathrm{Ar}-\mathrm{H}) .\end{array}$ & $\begin{array}{l}448.17 \\
\left(\mathrm{M}^{+}+1\right)\end{array}$ \\
\hline $6 e$ & $\begin{array}{l}1562(\mathrm{C}=\mathrm{N}) \\
1518,1491 \\
(\mathrm{C}=\mathrm{C}), 1248 \\
1171(\mathrm{C}-\mathrm{S}-\mathrm{C})\end{array}$ & $\begin{array}{l}\left.\text { 1.1-1.4 (t, } 3 \mathrm{H}, \mathrm{CH}_{2} \mathrm{CH}_{3}\right), 2.4\left(\mathrm{~s}, 3 \mathrm{H}, \mathrm{NCCH}_{3}\right), 2.6(\mathrm{~s}, 3 \mathrm{H}, \\
\left.\text { coumarin- } \mathrm{CH}_{3}\right), 3.7-4.1\left(\mathrm{q}, 2 \mathrm{H}, \mathrm{CH}_{2} \mathrm{CH}_{3}\right), 4.3\left(\mathrm{~s}, 3 \mathrm{H}, \mathrm{OCH}_{3}\right), 5.0 \\
\left(\mathrm{~s}, 2 \mathrm{H}, \mathrm{OCH}_{2}\right), 6.3\left(\mathrm{~s}, 1 \mathrm{H}, \mathrm{C}-\mathrm{H}_{3} \text { of coumarin }\right), 6.6(\mathrm{~s}, 1 \mathrm{H}, \mathrm{CH} \text { of } \\
\text { thiazoline }), 6.8-7.8(\mathrm{~m}, 7 \mathrm{H}, \mathrm{Ar}-\mathrm{H}) \text {. }\end{array}$ & $\begin{array}{l}464.16 \\
\left(\mathrm{M}^{+}+1\right)\end{array}$ \\
\hline $7 \mathbf{a}$ & $\begin{array}{l}1634(\mathrm{C}=\mathrm{N}) \\
1576,1529 \\
(\mathrm{C}=\mathrm{C}), 1260 \\
1187(\mathrm{C}-\mathrm{S}-\mathrm{C})\end{array}$ & $\begin{array}{l}1.2-1.5\left(\mathrm{~d}, 6 \mathrm{H}, \mathrm{CH}\left(\mathrm{CH}_{3}\right)_{2}\right), 2.2\left(\mathrm{~s}, 3 \mathrm{H}, \mathrm{NCC}_{3}\right), 2.6(\mathrm{~s}, 3 \mathrm{H}, \\
\left.\text { coumarin-CH}{ }_{3}\right), 2.9-3.2\left(\mathrm{~m}, 1 \mathrm{H}, \mathrm{CH}\left(\mathrm{CH}_{3}\right)_{2}\right), 5.0\left(\mathrm{~s}, 2 \mathrm{H}, \mathrm{OCH}_{2}\right), \\
6.3\left(\mathrm{~s}, 1 \mathrm{H}, \mathrm{C}-\mathrm{H}_{3} \text { of coumarin }\right), 6.5(\mathrm{~s}, 1 \mathrm{H}, \mathrm{CH} \text { of thiazoline }), 6.9- \\
7.8(\mathrm{~m}, 8 \mathrm{H}, \mathrm{Ar}-\mathrm{H}) .\end{array}$ & $\begin{array}{l}448.17 \\
\left(\mathrm{M}^{+}+1\right)\end{array}$ \\
\hline $7 b$ & $\begin{array}{l}1625(\mathrm{C}=\mathrm{N}) \\
1567,1520 \\
(\mathrm{C}=\mathrm{C}), 1260 \\
1187(\mathrm{C}-\mathrm{S}-\mathrm{C})\end{array}$ & $\begin{array}{l}1.3-1.5\left(\mathrm{~d}, 6 \mathrm{H}, \mathrm{CH}\left(\mathrm{CH}_{3}\right)_{2}\right), 2.4\left(\mathrm{~s}, 3 \mathrm{H}, \mathrm{NCC}{ }_{3}\right), 2.6(\mathrm{~s}, 3 \mathrm{H}, \\
\left.\text { coumarin- } \mathrm{CH}_{3}\right), 2.9-3.3\left(\mathrm{~m}, 1 \mathrm{H}, \mathrm{C} \underline{\mathrm{H}}\left(\mathrm{CH}_{3}\right)_{2}\right), 5.1\left(\mathrm{~s}, 2 \mathrm{H}, \mathrm{OCH}_{2}\right), \\
6.4\left(\mathrm{~s}, 1 \mathrm{H}, \mathrm{C}-\mathrm{H}_{3} \text { of coumarin }\right), 6.6(\mathrm{~s}, 1 \mathrm{H}, \mathrm{CH} \text { of thiazoline }), 6.8- \\
7.8(\mathrm{~m}, 7 \mathrm{H}, \mathrm{Ar}-\mathrm{H}) .\end{array}$ & $\begin{array}{c}526.08 \\
\left(\mathrm{M}^{+}+1\right)\end{array}$ \\
\hline $7 c$ & $\begin{array}{l}1630(\mathrm{C}=\mathrm{N}) \\
1556,1531 \\
(\mathrm{C}=\mathrm{C}), 1260 \\
1185(\mathrm{C}-\mathrm{S}-\mathrm{C})\end{array}$ & $\begin{array}{l}1.2-1.5\left(\mathrm{~d}, 6 \mathrm{H}, \mathrm{CH}\left(\mathrm{CH}_{3}\right)_{2}\right), 2.3\left(\mathrm{~s}, 3 \mathrm{H}, \mathrm{NCC}_{3}\right), 2.6(\mathrm{~s}, 3 \mathrm{H}, \\
\left.\text { coumarin- } \mathrm{CH}_{3}\right), 2.9-3.2\left(\mathrm{~m}, 1 \mathrm{H}, \mathrm{C} \underline{\mathrm{H}}\left(\mathrm{CH}_{3}\right)_{2}\right), 5.0\left(\mathrm{~s}, 2 \mathrm{H}, \mathrm{OCH}_{2}\right), \\
6.4\left(\mathrm{~s}, 1 \mathrm{H}, \mathrm{C}-\mathrm{H}_{3} \text { of coumarin }\right), 6.5(\mathrm{~s}, 1 \mathrm{H}, \mathrm{CH} \text { of thiazoline }), 6.9- \\
7.8(\mathrm{~m}, 7 \mathrm{H}, \mathrm{Ar}-\mathrm{H}) .\end{array}$ & $\begin{array}{c}482.13 \\
\left(\mathrm{M}^{+}+1\right)\end{array}$ \\
\hline
\end{tabular}


Table 2: Continued.

\begin{tabular}{|c|c|c|c|}
\hline $\begin{array}{l}\text { Compd. } \\
\text { No. }\end{array}$ & $\begin{array}{l}\text { IR }(\mathrm{KBr}) \\
\left(\dot{v}, \mathrm{~cm}^{-1}\right) \\
\end{array}$ & ${ }^{1} \mathrm{H}$ NMR (DMSO-d $6, \delta$ ppm) & $\begin{array}{c}\text { MS } \\
(\mathrm{m} / \mathrm{z})\end{array}$ \\
\hline 7d & $\begin{array}{l}1634(\mathrm{C}=\mathrm{N}) \\
1576,1525 \\
(\mathrm{C}=\mathrm{C}), 1260 \\
1187(\mathrm{C}-\mathrm{S}-\mathrm{C})\end{array}$ & $\begin{array}{l}1.1-1.5\left(\mathrm{~d}, 6 \mathrm{H}, \mathrm{CH}\left(\mathrm{CH}_{3}\right)_{2}\right), 2.3(\mathrm{~s}, 3 \mathrm{H}, \mathrm{NCCH} \\
\left.\mathrm{NH}_{3}\right), 2.6(\mathrm{~s}, 6 \mathrm{H}, \mathrm{Ar}- \\
\left.\mathrm{CH}_{3} \text { and coumarin- } \mathrm{CH}_{3}\right), 2.8-3.1\left(\mathrm{~m}, 1 \mathrm{H}, \mathrm{C} \underline{\mathrm{H}}\left(\mathrm{CH}_{3}\right)_{2}\right), 5.0(\mathrm{~s}, 2 \mathrm{H} \text {, } \\
\left.\mathrm{OCH}_{2}\right), 6.3\left(\mathrm{~s}, 1 \mathrm{H}, \mathrm{C}-\mathrm{H}_{3} \text { of coumarin }\right), 6.6(\mathrm{~s}, 1 \mathrm{H}, \mathrm{CH} \text { of } \\
\text { thiazoline }), 6.8-7.8(\mathrm{~m}, 7 \mathrm{H}, \mathrm{Ar}-\mathrm{H}) \text {. }\end{array}$ & $\begin{array}{l}462.18 \\
\left(\mathrm{M}^{+}+1\right)\end{array}$ \\
\hline $7 e$ & $\begin{array}{l}1630(\mathrm{C}=\mathrm{N}) \\
1576,1525 \\
(\mathrm{C}=\mathrm{C}), 1260 \\
1187(\mathrm{C}-\mathrm{S}-\mathrm{C})\end{array}$ & $\begin{array}{l}\text { 1.2-1.5 }\left(\mathrm{d}, 6 \mathrm{H}, \mathrm{CH}\left(\mathrm{C}_{3}\right)_{2}\right), 2.3\left(\mathrm{~s}, 3 \mathrm{H}, \mathrm{NCC}_{3}\right), 2.6(\mathrm{~s}, 3 \mathrm{H}, \\
\left.\text { coumarin- } \mathrm{CH}_{3}\right), 2.9-3.2\left(\mathrm{~m}, 1 \mathrm{H}, \mathrm{CH}\left(\mathrm{CH}_{3}\right)_{2}\right), 4.1\left(\mathrm{~s}, 3 \mathrm{H}, \mathrm{OCH}_{3}\right), \\
5.0\left(\mathrm{~s}, 2 \mathrm{H}, \mathrm{OCH}_{2}\right), 6.4\left(\mathrm{~s}, 1 \mathrm{H}, \mathrm{C}-\mathrm{H}_{3} \text { of coumarin }\right), 6.6(\mathrm{~s}, 1 \mathrm{H}, \mathrm{CH} \\
\text { of thiazoline }), 6.8-7.8(\mathrm{~m}, 7 \mathrm{H}, \mathrm{Ar}-\mathrm{H}) .\end{array}$ & $\begin{array}{l}478.18 \\
\left(\mathrm{M}^{+}+1\right)\end{array}$ \\
\hline $8 \mathbf{a}$ & $\begin{array}{l}1578(\mathrm{C}=\mathrm{N}) \\
1515,1453 \\
(\mathrm{C}=\mathrm{C}), 1250 \\
1181(\mathrm{C}-\mathrm{S}-\mathrm{C})\end{array}$ & $\begin{array}{l}2.2\left(\mathrm{~s}, 3 \mathrm{H}, \mathrm{NCCH}_{3}\right), 2.5\left(\mathrm{~s}, 3 \mathrm{H}, \text { coumarin- } \mathrm{CH}_{3}\right), 4.9(\mathrm{~s}, 2 \mathrm{H}, \\
\left.\mathrm{OCH}_{2}\right), 6.2\left(\mathrm{~s}, 1 \mathrm{H}, \mathrm{C}-\mathrm{H}_{3} \text { of coumarin }\right), 6.6(\mathrm{~s}, 1 \mathrm{H}, \mathrm{CH} \text { of } \\
\text { thiazoline }), 7.0-7.8(\mathrm{~m}, 13 \mathrm{H}, \mathrm{Ar}-\mathrm{H}) .\end{array}$ & $\begin{array}{l}482.17 \\
\left(\mathrm{M}^{+}+1\right)\end{array}$ \\
\hline $\mathbf{8 b}$ & $\begin{array}{l}1578(\mathrm{C}=\mathrm{N}) \\
1521,1460 \\
(\mathrm{C}=\mathrm{C}), 1250 \\
1180(\mathrm{C}-\mathrm{S}-\mathrm{C})\end{array}$ & $\begin{array}{l}2.3\left(\mathrm{~s}, 3 \mathrm{H}, \mathrm{NCCH}_{3}\right), 2.6\left(\mathrm{~s}, 3 \mathrm{H}, \text { coumarin- } \mathrm{CH}_{3}\right), 5.1(\mathrm{~s}, 2 \mathrm{H}, \\
\left.\mathrm{OCH}_{2}\right), 6.3\left(\mathrm{~s}, 1 \mathrm{H}, \mathrm{C}-\mathrm{H}_{3} \text { of coumarin }\right), 6.6(\mathrm{~s}, 1 \mathrm{H}, \mathrm{CH} \text { of } \\
\text { thiazoline }), 7.2-7.9(\mathrm{~m}, 12 \mathrm{H}, \mathrm{Ar}-\mathrm{H}) .\end{array}$ & $\begin{array}{l}560.08 \\
\left(\mathrm{M}^{+}+1\right)\end{array}$ \\
\hline $8 c$ & $\begin{array}{l}1578(\mathrm{C}=\mathrm{N}) \\
1520,1460 \\
(\mathrm{C}=\mathrm{C}), 1250 \\
1178(\mathrm{C}-\mathrm{S}-\mathrm{C})\end{array}$ & $\begin{array}{l}2.2\left(\mathrm{~s}, 3 \mathrm{H}, \mathrm{NCCH}_{3}\right), 2.6\left(\mathrm{~s}, 3 \mathrm{H}, \text { coumarin- } \mathrm{CH}_{3}\right), 5.0(\mathrm{~s}, 2 \mathrm{H}, \\
\left.\mathrm{OCH}_{2}\right), 6.2\left(\mathrm{~s}, 1 \mathrm{H}, \mathrm{C}-\mathrm{H}_{3} \text { of coumarin }\right), 6.5(\mathrm{~s}, 1 \mathrm{H}, \mathrm{CH} \text { of } \\
\text { thiazoline }), 7.1-7.8(\mathrm{~m}, 12 \mathrm{H}, \mathrm{Ar}-\mathrm{H}) .\end{array}$ & $\begin{array}{l}516.16 \\
\left(\mathrm{M}^{+}+1\right)\end{array}$ \\
\hline $8 d$ & $\begin{array}{l}1578(\mathrm{C}=\mathrm{N}) \\
1522,1453 \\
(\mathrm{C}=\mathrm{C}), 1250 \\
1176(\mathrm{C}-\mathrm{S}-\mathrm{C})\end{array}$ & $\begin{array}{l}2.2\left(\mathrm{~s}, 3 \mathrm{H}, \mathrm{NCCH}_{3}\right), 2.5\left(\mathrm{~s}, 6 \mathrm{H}, \mathrm{Ar}-\mathrm{CH}_{3} \text { and coumarin- } \mathrm{CH}_{3}\right), 5.0 \\
\left(\mathrm{~s}, 2 \mathrm{H}, \mathrm{OCH}_{2}\right), 6.2\left(\mathrm{~s}, 1 \mathrm{H}, \mathrm{C}-\mathrm{H}_{3} \text { of coumarin }\right), 6.5(\mathrm{~s}, 1 \mathrm{H}, \mathrm{CH} \text { of } \\
\text { thiazoline }), 7.1-7.8(\mathrm{~m}, 12 \mathrm{H}, \mathrm{Ar}-\mathrm{H}) \text {. }\end{array}$ & $\begin{array}{l}496.18 \\
\left(\mathrm{M}^{+}+1\right)\end{array}$ \\
\hline $8 e$ & $\begin{array}{l}1578(\mathrm{C}=\mathrm{N}) \\
1515,1457 \\
(\mathrm{C}=\mathrm{C}), 1250 \\
1178(\mathrm{C}-\mathrm{S}-\mathrm{C}) \\
\end{array}$ & $\begin{array}{l}2.2\left(\mathrm{~s}, 3 \mathrm{H}, \mathrm{NCCH}_{3}\right), 2.5\left(\mathrm{~s}, 3 \mathrm{H}, \text { coumarin- } \mathrm{CH}_{3}\right), 4.2(\mathrm{~s}, 3 \mathrm{H}, \\
\left.\mathrm{OCH}_{3}\right), 4.9\left(\mathrm{~s}, 2 \mathrm{H}, \mathrm{OCH}_{2}\right), 6.2\left(\mathrm{~s}, 1 \mathrm{H}, \mathrm{C}-\mathrm{H}_{3} \text { of coumarin }\right), 6.6(\mathrm{~s}, \\
1 \mathrm{H}, \mathrm{CH} \text { of thiazoline }), 7.0-7.8(\mathrm{~m}, 12 \mathrm{H}, \mathrm{Ar}-\mathrm{H}) .\end{array}$ & $\begin{array}{l}512.17 \\
\left(\mathrm{M}^{+}+1\right)\end{array}$ \\
\hline $9 \mathbf{a}$ & $\begin{array}{l}1578(\mathrm{C}=\mathrm{N}) \\
1517,1463 \\
(\mathrm{C}=\mathrm{C}), 1250 \\
1179(\mathrm{C}-\mathrm{S}-\mathrm{C})\end{array}$ & $\begin{array}{l}2.2\left(\mathrm{~s}, 3 \mathrm{H}, \mathrm{NCCH}_{3}\right), 2.4\left(\mathrm{~s}, 6 \mathrm{H}, \mathrm{Ar}-\mathrm{CH}_{3} \text { and coumarin- } \mathrm{CH}_{3}\right), 4.9 \\
\left(\mathrm{~s}, 2 \mathrm{H}, \mathrm{OCH}_{2}\right), 6.3\left(\mathrm{~s}, 1 \mathrm{H}, \mathrm{C}-\mathrm{H}_{3} \text { of coumarin }\right), 6.6(\mathrm{~s}, 1 \mathrm{H}, \mathrm{CH} \text { of } \\
\text { thiazoline }), 7.0-7.8(\mathrm{~m}, 12 \mathrm{H}, \mathrm{Ar}-\mathrm{H}) .\end{array}$ & $\begin{array}{l}496.18 \\
\left(\mathrm{M}^{+}+1\right)\end{array}$ \\
\hline $9 b$ & $\begin{array}{l}1558(\mathrm{C}=\mathrm{N}) \\
1515,1453 \\
(\mathrm{C}=\mathrm{C}), 1250 \\
1178(\mathrm{C}-\mathrm{S}-\mathrm{C})\end{array}$ & $\begin{array}{l}2.3\left(\mathrm{~s}, 3 \mathrm{H}, \mathrm{NCCH}_{3}\right), 2.6\left(\mathrm{~s}, 6 \mathrm{H}, \mathrm{Ar}-\mathrm{CH}_{3} \text { and coumarin- } \mathrm{CH}_{3}\right), 5.0 \\
\left(\mathrm{~s}, 2 \mathrm{H}, \mathrm{OCH}_{2}\right), 6.4\left(\mathrm{~s}, 1 \mathrm{H}, \mathrm{C}-\mathrm{H}_{3} \text { of coumarin }\right), 6.6(\mathrm{~s}, 1 \mathrm{H}, \mathrm{CH} \text { of } \\
\text { thiazoline }), 7.1-7.9(\mathrm{~m}, 11 \mathrm{H}, \mathrm{Ar}-\mathrm{H}) .\end{array}$ & $\begin{array}{c}574.11 \\
\left(\mathrm{M}^{+}+1\right)\end{array}$ \\
\hline $9 c$ & $\begin{array}{l}1587(\mathrm{C}=\mathrm{N}) \\
1515,1457 \\
(\mathrm{C}=\mathrm{C}), 1250 \\
1178(\mathrm{C}-\mathrm{S}-\mathrm{C})\end{array}$ & $\begin{array}{l}2.3\left(\mathrm{~s}, 3 \mathrm{H}, \mathrm{NCCH}_{3}\right), 2.6\left(\mathrm{~s}, 6 \mathrm{H}, \mathrm{Ar}-\mathrm{CH}_{3} \text { and coumarin- } \mathrm{CH}_{3}\right), 4.9 \\
\left(\mathrm{~s}, 2 \mathrm{H}, \mathrm{OCH}_{2}\right), 6.3\left(\mathrm{~s}, 1 \mathrm{H}, \mathrm{C}-\mathrm{H}_{3} \text { of coumarin }\right), 6.6(\mathrm{~s}, 1 \mathrm{H}, \mathrm{CH} \text { of } \\
\text { thiazoline }), 7.0-7.8(\mathrm{~m}, 11 \mathrm{H}, \mathrm{Ar}-\mathrm{H}) .\end{array}$ & $\begin{array}{c}530.16 \\
\left(\mathrm{M}^{+}+1\right)\end{array}$ \\
\hline 9d & $\begin{array}{l}1572(\mathrm{C}=\mathrm{N}) \\
1512,1459 \\
(\mathrm{C}=\mathrm{C}), 1250 \\
1180(\mathrm{C}-\mathrm{S}-\mathrm{C})\end{array}$ & $\begin{array}{l}2.3\left(\mathrm{~s}, 3 \mathrm{H}, \mathrm{NCCH}_{3}\right), 2.5\left(\mathrm{~s}, 9 \mathrm{H}, 2 \mathrm{Ar}-\mathrm{CH}_{3} \text { and coumarin- } \mathrm{CH}_{3}\right), 5.0 \\
\left(\mathrm{~s}, 2 \mathrm{H}, \mathrm{OCH}_{2}\right), 6.3\left(\mathrm{~s}, 1 \mathrm{H}, \mathrm{C}-\mathrm{H}_{3} \text { of coumarin }\right), 6.6(\mathrm{~s}, 1 \mathrm{H}, \mathrm{CH} \text { of } \\
\text { thiazoline }), 7.0-7.8(\mathrm{~m}, 11 \mathrm{H}, \mathrm{Ar}-\mathrm{H}) .\end{array}$ & $\begin{array}{l}510.18 \\
\left(\mathrm{M}^{+}+1\right)\end{array}$ \\
\hline $9 e$ & $\begin{array}{l}1581(\mathrm{C}=\mathrm{N}) \\
1520,1450 \\
(\mathrm{C}=\mathrm{C}), 1250 \\
1181(\mathrm{C}-\mathrm{S}-\mathrm{C})\end{array}$ & $\begin{array}{l}2.3\left(\mathrm{~s}, 3 \mathrm{H}, \mathrm{NCCH}_{3}\right), 2.6\left(\mathrm{~s}, 6 \mathrm{H}, \mathrm{Ar}-\mathrm{CH}_{3} \text { and coumarin- } \mathrm{CH}_{3}\right), 4.1 \\
\left(\mathrm{~s}, 3 \mathrm{H}, \mathrm{OCH}_{3}\right), 4.9\left(\mathrm{~s}, 2 \mathrm{H}, \mathrm{OCH}_{2}\right), 6.3\left(\mathrm{~s}, 1 \mathrm{H}, \mathrm{C}-\mathrm{H}_{3} \text { of coumarin }\right), \\
6.6(\mathrm{~s}, 1 \mathrm{H}, \mathrm{CH} \text { of thiazoline }), 7.0-7.8(\mathrm{~m}, 11 \mathrm{H}, \mathrm{Ar}-\mathrm{H}) .\end{array}$ & $\begin{array}{c}526.18 \\
\left(\mathrm{M}^{+}+1\right)\end{array}$ \\
\hline
\end{tabular}




\section{Materials and method}

Cell suspension of bacterial strains was prepared from $48 \mathrm{hrs}$ old cultures grown on nutrient agar (NA) in sterilized water ${ }^{26}$. One $\mathrm{mL}$ suspension was added to Petri dishes of 9 $\mathrm{cm}$ in diameter and then $15 \mathrm{~mL}$ of $\mathrm{NA}$ was poured into the plates. Plates were shaken gently to homogenize the inocula.

Sterile 5-mm filter paper disc (Whatman) was saturated with $10 \mu \mathrm{L}$ solutions of the test compounds or gatifloxacin as a reference drug (53 $\mu$ mol- $\mathrm{mL}^{-1}$ in DMSO). In addition, other disks were impregnated with the solvent (DMSO) and served as a negative control. The discs were then dried for $1 \mathrm{hr}$ and placed in the center of each plate. The seeded plates were incubated at $35 \pm 2{ }^{\circ} \mathrm{C}$ for $24-48 \mathrm{hrs}$. The radii of inhibition zones (in $\mathrm{mm}$ ) were measured in triplicate and the results are given in table 3.

\section{b) Antifungal activity \\ Organisms and culture conditions}

The used Sabouraud Agar (SA) media were prepared in Assiut University Mycological Center (AUMC), Assiut University, Assiut. The antifungal activity of compounds 4a-d and 6-9a-e was determined according to the agar disc diffusion method ${ }^{26}$.

Seven pathogenic (Trichophyton rubrum (Castellani) Sabouraud AUMC 1145 and Candida albicans (Robin) Berkhout AUMC 421), phytopathogenic (Fusarium oxysporum Schlechtendal AUMC 208) and food deteriorating fungal species (Aspergillus flavus Link AUMC 3372, Aspergillus niger Van Tieghem AUMC 3364, Geotrichum candidum Link AUMC 228 and Scopulariopsis brevicaulis (Saccardo) Bainier AUMC 363) were used in the present study.

\section{Materials and method}

Spore suspension in sterile distilled water was prepared from 2-5 days old culture of the test fungi growing on Sabouraud agar (SA) medium $^{26}$. The final spore concentration was nearly $5 \times 10^{4}$ spores- $\mathrm{mL}^{-1}$. About $15 \mathrm{~mL}$ of growth medium was introduced on sterilized Petri dishes of $9 \mathrm{~cm}$ diameter and inoculated with $1 \mathrm{~mL}$ of spore suspension. Plates were shaken gently to homogenize the inocula. Antifungal activity of the test compounds 4a-d and 6-9a-e was performed by the standard agar disc diffusion method as follows.
Sterile 5-mm filter paper disc (Whatman) was saturated with $10 \mu \mathrm{L}$ solutions of the test compound or ketoconazole $\left(40 \mu \mathrm{mol}-\mathrm{mL}^{-1}\right.$ in DMSO). In addition, other disks were impregnated with the solvent (DMSO) and served as a negative control. The disks were then dried for $1 \mathrm{hr}$ and placed in the center of each plate. The seeded plates were incubated at $28 \pm 2{ }^{\circ} \mathrm{C}$ for 7 days. The radii of inhibition zones (in $\mathrm{mm}$ ) of triplicate sets were measured at successive intervals during the incubation period and results are presented in table 4 .

\section{RESULTS AND DISCUSSION}

\section{Chemistry}

The starting material 4-methyl-7-(2oxopropoxy)-2H-chromen-2-one (2) was prepared according to a reported procedure through reaction of 7-hydroxy-4-methyl- $2 \mathrm{H}$ chromen-2-one (1) with chloroacetone in the presence of anhydrous potassium carbonate using acetone as a solvent ${ }^{25}$. Structure of compound 2 was confirmed by comparison of its physical and spectral data with the reported ones ${ }^{25}$. ${ }^{1} \mathrm{H}$ NMR spectrum of compound 2 showed two singlets at $\delta 2$ and $2.10 \mathrm{ppm}$ (two methyl groups), singlet at $\delta 4.9 \mathrm{ppm}\left(\mathrm{OCH}_{2}\right)$, singlet at $\delta 6.3 \mathrm{ppm}\left(\mathrm{C}-\mathrm{H}_{3}\right.$ of coumarin ring) besides multiplet $(2 \mathrm{H})$ at $6.8-7.3 \mathrm{ppm}$ corresponding to $\mathrm{C}-\mathrm{H}_{6}$ and $\mathrm{C}-\mathrm{H}_{8}$ of coumarin, in addition to a doublet $(1 \mathrm{H})$ at 7.4-7.6 ppm corresponding to $\mathrm{C}-\mathrm{H}_{5}$ coumarin.

The key intermediates, $N$-alkyl/aryl-2-[1(4-methyl-2-oxo-2H-chromen-7-yloxy)propan2-ylidene]hydrazine carbothioamides (4a-d) were prepared by condensation of thiosemicarbazides (3a-d) derived from an aryl or alkyl isothiocyanates and hydrazine ${ }^{19}$, with compound 2 (Scheme 1). Structures of compounds 4a-d were confirmed from IR, ${ }^{1} \mathrm{H}$ NMR spectra as well as elemental analyses (Tables 1 and 2). IR spectrum showed two bands at 3390 and $3350 \mathrm{~cm}^{-1}$ (two $\mathrm{NH}$ ) and a band at $1625 \mathrm{~cm}^{-1}$ corresponding to $\mathrm{C}=\mathrm{N}$. ${ }^{1} \mathrm{H}$ NMR spectrum revealed the presence of two broad singlet (two $\mathrm{NH}$ groups) exchangeable with $\mathrm{D}_{2} \mathrm{O}$, singlet at $\delta 2.3 \mathrm{ppm}\left(\mathrm{C}_{4}-\mathrm{CH}_{3}\right)$, singlet at $\delta 5 \mathrm{ppm}\left(\mathrm{OCH}_{2}\right)$, singlet $\left(\mathrm{C}-\mathrm{H}_{3}\right.$ of coumarin), in addition to characteristic patterns of coumarin aromatic protons. 
<smiles>Cc1cc(=O)oc2cc(O)ccc12</smiles>

1

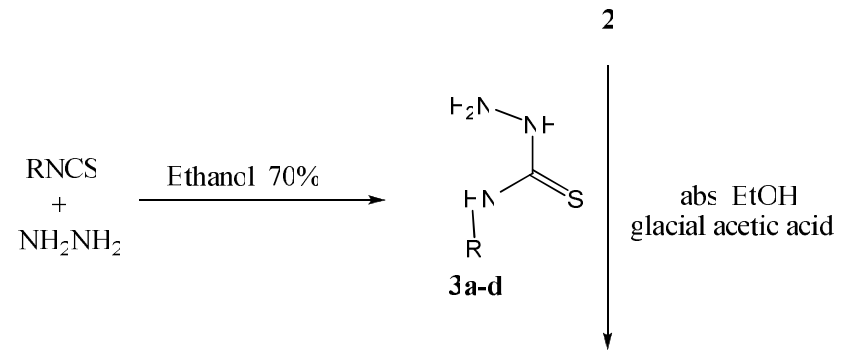<smiles>[R]NPC(=S)N/N=C(\C)COc1ccc2c(C)cc(=O)oc2c1</smiles>

$$
\begin{aligned}
& \mathrm{R}=\mathrm{C}_{2} \mathrm{H}_{5}, \mathrm{CH}\left(\mathrm{CH}_{3}\right)_{2}, \mathrm{C}_{6} \mathrm{H}_{5}, p-\mathrm{CH}_{3} \mathrm{C}_{6} \mathrm{H}_{4} \\
& \mathrm{R}^{1}=\mathrm{H}, \mathrm{Br}, \mathrm{Cl}, \mathrm{CH}_{3}, \mathrm{OCH}_{3}
\end{aligned}
$$

Scheme 1: Synthetic route of compounds 4a-d and 6-9a-e.

\begin{tabular}{|c|c|c|c|c|}
\hline \multirow{3}{*}{$\begin{array}{l}\text { Compd. } \\
\text { No. }\end{array}$} & \multicolumn{4}{|c|}{$\%$ Inhibition zones } \\
\hline & \multirow{2}{*}{$\begin{array}{c}\text { Gram-Positive } \\
\text { B. cereus }\end{array}$} & \multicolumn{3}{|c|}{ Gram-Negative } \\
\hline & & E. coli & P. aeruginosa & S. marcescens \\
\hline $4 \mathbf{a}$ & 24.2 & 27.8 & -- & 34.1 \\
\hline $4 b$ & 23.4 & 32.4 & -- & 32.8 \\
\hline 4c & 22.2 & 28.7 & -- & -- \\
\hline $\mathbf{6 a}$ & 26.5 & -- & -- & -- \\
\hline $6 \mathbf{b}$ & 26.5 & 33.3 & -- & 88.2 \\
\hline 6c & 52.9 & -- & -- & 64.7 \\
\hline $6 \mathbf{e}$ & 35.3 & 60.0 & -- & 29.4 \\
\hline $7 \mathbf{a}$ & 23.5 & 46.7 & -- & -- \\
\hline $7 \mathbf{b}$ & 29.4 & 53.3 & -- & 44.1 \\
\hline $7 c$ & 20.6 & -- & -- & -- \\
\hline 7d & -- & 40.0 & 50.0 & -- \\
\hline $7 e$ & -- & -- & -- & 20.6 \\
\hline $8 \mathbf{a}$ & 29.4 & -- & -- & 58.8 \\
\hline $\mathbf{8 b}$ & 38.2 & -- & -- & 67.6 \\
\hline $8 c$ & 41.2 & -- & -- & 44.1 \\
\hline $9 \mathrm{c}$ & 29.4 & -- & 41.7 & -- \\
\hline Gatifloxacin & 100 & 100 & 100 & 100 \\
\hline
\end{tabular}

Table 3: Percentage inhibition zones of compounds 4a-c, 6a-c, 6e, 7a-e, 8a-c, 9c and gatifloxacin.

-- No inhibition. 
Table 4: Percentage inhibition zones of compounds 4a-c, 6a-c, 6e, 7b, 8a-c and ketoconazole.

\begin{tabular}{||c|c|c|c|c|c|c||}
\hline \multirow{2}{*}{$\begin{array}{c}\text { Compd. } \\
\text { No. }\end{array}$} & \multicolumn{6}{|c||}{ \% Inhibition zones } \\
\cline { 2 - 7 } & C. albicans & F. oxysporum & $\begin{array}{c}\text { A. } \\
\text { flavus }\end{array}$ & A. niger & G. candidum & S. brevicaulis \\
\hline $\mathbf{4 a}$ & 25.8 & 56.8 & -- & -- & 37.2 & -- \\
\hline $\mathbf{4 b}$ & -- & 48.9 & -- & -- & 25.9 & -- \\
\hline $\mathbf{4 c}$ & -- & 50.4 & -- & -- & -- & 15.2 \\
\hline $\mathbf{6 a}$ & -- & 125.0 & 58.8 & 75.0 & -- & -- \\
\hline $\mathbf{6 b}$ & -- & 150.0 & 29.41 & 62.5 & 31.2 & -- \\
\hline $\mathbf{6 c}$ & -- & 162.5 & 58.8 & 75.0 & 46.9 & $10^{*}$ \\
\hline $\mathbf{6 e}$ & 25.0 & 162.5 & 58.8 & 83.3 & 37.5 & -- \\
\hline $\mathbf{7 b}$ & -- & 125.0 & -- & 50.0 & -- & $9^{*}$ \\
\hline $\mathbf{8 a}$ & -- & -- & 29.4 & -- & -- & $20^{*}$ \\
\hline $\mathbf{8 b}$ & -- & -- & 38.2 & -- & -- & $23^{*}$ \\
\hline $\mathbf{8 c}$ & -- & -- & 41.2 & -- & -- & $15^{*}$ \\
\hline Ketoconazole & 100 & 100 & 100 & 100 & 100 & -- \\
\hline
\end{tabular}

*In mm -- No inhibition.

In the present investigation, 7-[2-(3alkyl/aryl-4-arylthiazol-2 $(3 H)$-ylidene)hydrazono)propoxy]-4-methyl-2H-chromen-2-ones (6-9a-e) were prepared by refluxing thiosemicarbazone derivatives (4a-d) with equimolar amount of phenacyl bromides (5a-e) in the presence of anhydrous sodium acetate in absolute ethanol for 6-8 hrs (Scheme 1).

The IR spectra of compounds 6-9a-e are characterized by some general features such as lack of the characteristic bands due to $\mathrm{NH}$ and NCS functions and exhibited a band attributed to $\mathrm{C}=\mathrm{N}$ stretching vibration at $1634-1562 \mathrm{~cm}^{-1}$. Moreover, all compounds showed the characteristic bands at 1577-1500 and 1523$1478 \mathrm{~cm}^{-1}$ attributed to $\mathrm{C}=\mathrm{C}$ function as well as bands at $1255-1248$ and $1187-1171 \mathrm{~cm}^{-1}$ due to C-S-C ${ }^{27}$.

${ }^{1} \mathrm{H} \quad$ NMR spectra of 7-[2-(3-ethyl-4arylthiazol-2(3H)-ylidene)hydrazono)propoxy]4-methyl-2H-chromen-2-ones (6a-e) are characterized by some general features such as the presence of a triplet signal at $\delta 1.1-1.3 \mathrm{ppm}$ and quartet at 3.7-4.4 ppm corresponding to $\mathrm{C}_{2} \mathrm{H}_{5}$ moiety, a singlet signal at $\delta 5-5.1 \mathrm{ppm}$ of $\mathrm{OCH}_{2}$ group, a singlet signal at $\delta 6.3 \mathrm{ppm}$ corresponding to the coumarin $\mathrm{H}_{3}$, a singlet signal at $\delta 6.6-6.7 \mathrm{ppm}$ corresponding to the thiazoline proton, in addition to disappearance of the signals corresponding to the $\mathrm{NH}$ groups.

Mass spectrum of compound $\mathbf{6 c}$ revealed a molecular ion peak $\mathrm{M}^{+}$at $\mathrm{m} / \mathrm{z} 467.1(100 \%)$ corresponding to the molecular weight of this compound which is also the base peak. Also, the spectrum showed a peak at $\mathbf{M}^{+}+2(\mathrm{~m} / \mathrm{z}$ $469.1,36 \%$ ) due to $\mathrm{CH}^{37} \mathrm{CINOS}$.

${ }^{1} \mathrm{H}$ NMR spectra of 7-[2-(3-isopropyl-4arylthiazol-2(3H)-ylidene)hydrazono)propoxy]4-methyl- $2 H$-chromen-2-ones (7a-e) are characterized by some general features such as the presence of a doublet signal at $\delta$ 1.1-1.5 $\mathrm{ppm}$ and multiplet at 2.8-3.3 ppm corresponding to $\mathrm{CH}\left(\mathrm{CH}_{3}\right)_{2}$ moiety, a singlet signal at $\delta 5-5.1 \mathrm{ppm}$ of $\mathrm{OCH}_{2}$ group, a singlet signal at $\delta 6.3 \mathrm{ppm}$ corresponding to the coumarin $\mathrm{H}_{3}$, a singlet signal at $\delta 6.6-6.7 \mathrm{ppm}$ corresponding to the thiazoline proton, in addition to disappearance of the signals corresponding to $\mathrm{NH}$ groups.

Mass spectrum of compound 7a (M.Wt. 447.16) revealed a molecular ion peak $\mathrm{M}^{+}$at $\mathrm{m} / z \quad 447.1$ (100\%) corresponding to the molecular weight of this compound which is also the base peak.

${ }^{1} \mathrm{H}$ NMR spectra of compounds 8a-e and 9a-e are characterized by some general features such as the presence of a singlet signal at $\delta$ 4.9$5.0 \mathrm{ppm}$ of $\mathrm{OCH}_{2}$ group, a singlet signal at $\delta$ 6.2-6.4 ppm corresponding to the coumarin $\mathrm{H}_{3}$, a singlet signal at $\delta 6.5-6.6 \mathrm{ppm}$ corresponding to the thiazoline proton, besides the characteristic pattern of aromatic protons. Additionally the signals corresponding to the NH groups have disappeared.

Mass spectrum of compound 9c revealed the molecular ion peak $\mathrm{M}^{+}$at $\mathrm{m} / \mathrm{z} \quad 529.1$ corresponding to the base peak (100\%). Also, 
the spectrum showed a peak $\mathrm{M}^{+}+2$ at $\mathrm{m} / z 531.1$ (38.7\%) due to ${ }^{37} \mathrm{Cl}$.

\section{Antimicrobial activity and SAR}

Antibacterial activity

Results of the antibacterial activity (Table

3 ) indicated that $S$. aureus and M. luteus were completely resistant to the tested compounds, while B. cereus, E. coli and S. marcescens were the most sensitive organisms to the tested compounds. Compounds $4 \mathrm{~d}$ ( $\mathrm{R}=p$-tolyl), $\mathbf{6 d}$ $\left(\mathrm{R}=\mathrm{C}_{2} \mathrm{H}_{5}\right.$ and $\left.\mathrm{R}^{1}=\mathrm{CH}_{3}\right), \mathbf{8 d}\left(\mathrm{R}=\mathrm{C}_{6} \mathrm{H}_{5}\right.$ and $\mathrm{R}^{1}=$ $\left.\mathrm{CH}_{3}\right), 8 \mathbf{e}\left(\mathrm{R}=\mathrm{C}_{6} \mathrm{H}_{5}\right.$ and $\left.\mathrm{R}^{1}=\mathrm{OCH}_{3}\right), 9 \mathbf{a}(\mathrm{R}=p$ tolyl and $\left.\mathrm{R}^{1}=\mathrm{H}\right), \mathbf{9 b}\left(\mathrm{R}=p\right.$-tolyl and $\left.\mathrm{R}^{1}=\mathrm{Br}\right)$, 9d $\left(\mathrm{R}=p\right.$-tolyl and $\left.\mathrm{R}^{1}=\mathrm{CH}_{3}\right)$ and $9 \mathrm{e}(\mathrm{R}=p$ tolyl and $\mathrm{R}^{1}=\mathrm{OCH}_{3}$ ) were completely inactive against all the tested organisms. Also the test compounds were inactive against $P$. aeroginosa except compounds $\mathbf{7 d}$ and $\mathbf{9 c}$ which are moderately active. On the other hand, the majority of the tested compounds appeared to be weakly active against $B$. cereus. Nevertheless some of them, $\mathbf{6 c}, \mathbf{6 e}, \mathbf{8 b}$ and $\mathbf{8 c}$ showed moderate activity, and, compounds $\mathbf{6 e}$, $\mathbf{7 a}, \mathbf{7 b}$, and $\mathbf{7 d}$ exhibited moderate to good activity against $E$. coli correlated to the standard drug gatifloxacin. Moreover, some of the test compounds showed good activity against $S$. marcescens and compound $\mathbf{6 b}$ exhibited excellent activity.

\section{SAR}

1- Generally, it was observed that compounds containing thiazoline nucleus (6-9a-e) seems to be more effective than their precursor's hydrazine carbothioamides (4a-d).

2- The most active compounds seem to be compounds containing $\mathrm{Cl}$ or $\mathrm{Br}$ as an $\mathrm{R}^{1}$ substituent.

3- It was also noticed that the introduction of a $p$-tolyl group in compounds 9a-e resulted in a decrease of their antibacterial activity. Also, the ethyl substituent at $R$ seems to be crucial for the antibacterial activity against S. marcescens.

\section{Antifungal activity}

Results of antifungal activity (Table 4) revealed that all the tested compounds were inactive against $T$. rubrum. They were also inactive against $C$. albicans, except for compounds $4 \mathbf{a}$ and $\mathbf{6 e}$ since they showed $25 \%$ activity compared to ketoconazole. Several compounds showed weak to moderate activity against $S$. brevicaulis, while the reference drug was completely inactive. Compounds $\mathbf{6 a}, \mathbf{6 b}$, 6c, 6e and $\mathbf{7 b}$ were even more active than ketoconazole against $F$. oxysporum. The most active compounds were $\mathbf{6 b}, \mathbf{6 c}, \mathbf{7 b}, \mathbf{8 b}$ and $\mathbf{8 c}$ comprising $\mathrm{Cl}$ or $\mathrm{Br}$ as an $\mathrm{R}^{1}$ substituent.

\section{SAR}

1- Again, it was observed that compounds containing thiazoline nucleus (6-9a-e) seems to be more effective than their precursor's hydrazine carbothioamides (4a-d).

2- The most active compounds seem to be compounds containing electron withdrawing group $(\mathrm{Cl}$ or $\mathrm{Br})$ as an $\mathrm{R}^{1}$ substituent.

3- It was also noticed that the introduction of a bulky group ( $p$-tolyl) in compounds 9a-e resulted in a complete loss of antifungal activity while small group (ethyl substituent) at $\mathrm{R}$ seems to be crucial for the antifungal activity against $F$. oxysporum, A. flavus and A. niger.

\section{Conclusions}

A number of 7-[2-(3-alkyl/aryl-4arylthiazol-2(3H)-ylidene)hydrazono)propoxy]4-methyl-2H-chromen-2-ones (6-9a-e) were prepared and tested for their antimicrobial activity. The antibacterial data indicated that most of the test compounds showed moderate to good activity against $B$. cereus, E. coli and $S$. marcescens and some of them showed antibacterial activity against and $P$. aeroginosa. On the other hand, they showed no activity against $S$. aureus and M. luteus. Results of antifungal activity revealed that all the tested compounds were inactive against $T$. rubrum and $C$. albicans, except for compounds $\mathbf{4 a}$ and 6e. Several compounds showed weak to moderate activity against $S$. brevicaulis, while the reference drug was completely inactive. Compounds $\mathbf{6 a}, \mathbf{6 b}, \mathbf{6 c}, \mathbf{6 e}$ and $\mathbf{7 b}$ were even more active than ketoconazole against $F$. oxysporum. Generally, compounds containing thiazoline nucleus (6-9a-e) seems to be more effective both as antibacterial and antifungal than their precursor's hydrazine carbothioamides (4a-d). $\mathrm{N}$-ethyl series (6a-e) was the most active both as antibacterial and antifungal agents among the series. It was also noticed that the halo substituted derivatives were the most active ones both as antibacterial and antifungal agents. 


\section{REFERENCES}

1- R. Rajasekaran, G. K. Rao, S. P. N. Pai and A. Ranjan, "Design, synthesis, antimicrobial and in-vitro antioxidant activity of substituted 2H-benzopyran-2-one derivatives", Int. J. Chem. Tech. Res., 3, 555-559 (2011).

2- A. O. Olayinka and N. C. Obinna, "Microwave-assisted synthesis and evaluation of anti-microbial activity of 3\{3-(S-aryl and S-heteroaromatic)acryloyl $\}-$ $2 H$-chromen-2-one derivatives", J. Heterocycl. Chem., 47, 179-187 (2010).

3- D. I. Brahnbhatt, J. M. Gajera, V. P. Pandya and M. A. Patel, "Synthesis of 3(6-aryl-pyridin-2-yl) and 8-(6-aryl-pyridin2yl)coumarins", Ind. J. Chem., 46 (B), 869-871 (2007).

4- R. Sharma and V. Arya, "A review on fruits having anti-diabetic potential", $J$. Chem. Pharm. Res., 3, 204-212 (2011).

5- C. P. K. Reddy, V. M. Goud, N. Sreenivasulu and R. Prasad, "Design, synthesis and chemical characterization of some novel coumarin compounds and evaluation of their biological activity", Int. J. Pharm. World Res., 1, 1-19 (2010).

6- R. D. H. Murrey, D. Medez and S. A. Brown, "The Natural Coumarins Occurrences. Chemistry and Biochemistry", Wiley Interscience, John Wiley and Sons, New York, 1982, pp. 97107.

7- C. Rakesh and K. S. Pitre, "Structural modification of coumarin for its increased anticoagulation potency", Can. J. Chem. Engin. Technol., 1 (2), 7-15 (2010).

8- T. Olomola, R. Llein, N. Mautsa, Y. Sayed and P. T. Kaye, "Synthesis and evaluation of coumarin derivatives as potential dualaction HIV-1 protease and reverse transcriptase inhibitors", Bioorg. Med. Chem., 1, 1964-1971 (2013).

9- N. H. Patel, A. K. Patel, C. V. Patel, A. P. Apoorva and D. I. Brhambhat, "Synthesis and spectral characterization of some 3-(1aryl-9,10-dihydro-4-azaphenanthren-3-

yl)coumarins", Arkivoc, 2, 283-291 (2010).

10- J. K. Gupta, P. K. Sharma, R. Dudhe, A. Chaudhary, A. Singh and S. Kashyap, "Analgesic study of novel pyrimidine 
derivatives linked with coumarin moiety", Med. Chem. Res., 21, 1625-1632 (2010).

11- P. K. Monga, D. Sharma and A. Dubey, "Comparative study of microwave and conventional synthesis and pharmacological activity of coumarins", $\boldsymbol{J}$. Chem. Pharm. Res., 4, 822-850 (2012).

12- C. L. Freel Meyers, M. Oberthür, H. Xu, L. Heide, D. Kahne and C. T. Walsh, "Characterization of NovP and NovN: Completion of novobiocin biosynthesis by sequential tailoring of the noviosyl ring", Angew. Chem. Int. Ed. Engl., 43, 67-70 (2004).

13- L. Heide, "Genetic engineering of antibiotic biosynthesis for the generation of new aminocoumarins", Biotechnol. Adv., 27, 1006-1014 (2009).

14- A. Maxwell and D. M. Lawson, "The ATP-binding site of type II topoisomerases as a target for antibacterial drugs", Curr. Top. Med. Chem., 3, 283-303 (2003).

15- S. S. Sahoo, S. Shukla, S. Nandy and H. B. Sahoo, "Synthesis of novel coumarin derivatives and its biological evaluations", Eur. J. Exp. Biol., 2, 899-908 (2012).

16- J. A. Lessa, M. A. Soares, R. G. dos Santos, I. C. Mendes, L. B. Salum, H. N. Daghestani, A. D. Andricopulo, B. W. Day, A. Vogt and H. Beraldo, "Gallium(III) complexes with 2acetylpyridine-derived thiosemicarbazones: Antimicrobial and cytotoxic effects and investigation on the interactions with tubulin", Biometals, 26 (1), 151-165 (2013).

17- N. Bharti, F. Athar, M. R. Maurya and A. Azam, "Synthesis, characterization and invitro anti-amoebic activity of new palladium(II) complexes with 5nitrothiophene-2-carboxaldehyde $\quad N(4)$ substituted thiosemicarbazones", Bioorg. Med. Chem., 12, 4679-4684 (2004).

18- M. Sheikhy, A. R. Jalilian, A. Novinrooz and F. Motamedi-Sedeh, "Synthesis and in-vitro antibacterial evaluation of some thiosemicarbazides and thiosemicarbazones", J. Biomed. Sci. and Eng., 5, 3942 (2012).

19- M. Jagadeesh, V. A. Kumar, C. Ramachandraiah and A. V. Reddy, "New halogenated thiosemicarbazones as potential antimicrobial agents: Synthesis and spectral characterizations", J. Appl. Pharm. Sci., 3, 111-115 (2013).

20- N. Fujii, J. P. Mallari, E. J. Hansell, Z. Mackey, P. Doyle, Y. M. Zhou, J. Gut, P. J. Rosenthal, J. H. McKerrow and R. K. Guy, "Discovery of potent thiosemicarbazone inhibitors of rhodesain and cruzan", Bioorg. Med. Chem. Lett., 15, 121-123 (2005).

21- J. R. Gujarathi, N. S. Pawar and R. S. Bendrea, "Synthesis, physicochemical and biological evaluation of Co (II) complexes derived from 5-chloro-2-hydroxy acetophenone $N(4)$ methyl thiosemicarbazone", J. Chem. Pharm. Res., 5 (7), 161-168 (2013).

22- K. Aslam, M. K. Khosa, N. Jahan and S. Nosheen, "Synthesis and applications of coumarins", Pak. J. Pharm. Sci., 23, 449454 (2010). 
23- D. Barton and W. D. Ollis, "Comprehensive Organic Chemistry", Ed. D. N. Jones, Pergamon Press, New York, 1979, p. 453.

24- R. M. Cowper and L. H. Davidson, "Organic Syntheses", Ed. R. Adams, John Wiley and Sons, New York, 1943, p. 480.

25- J. M. Patel and S. S. Soman, "Studies in synthesis of new psoralenamines", $\boldsymbol{J}$. Heterocycl. Chem., 47, 379-383 (2010).
26- H. William, "Microbiological Assay, An Introduction to Quantitative Principles and Evaluation", Academic Press, New York, 1977, pp. 1-86.

27- N. S. Habib and S. A. El-Hawash, "Synthesis and anti-microbial testing of thiazolinyl-thiazolidinonyl-quinoxalines and 1,2,4-triazolo[4,3-a]quinoxalines", Pharmazie, 52, 594-598 (1997).
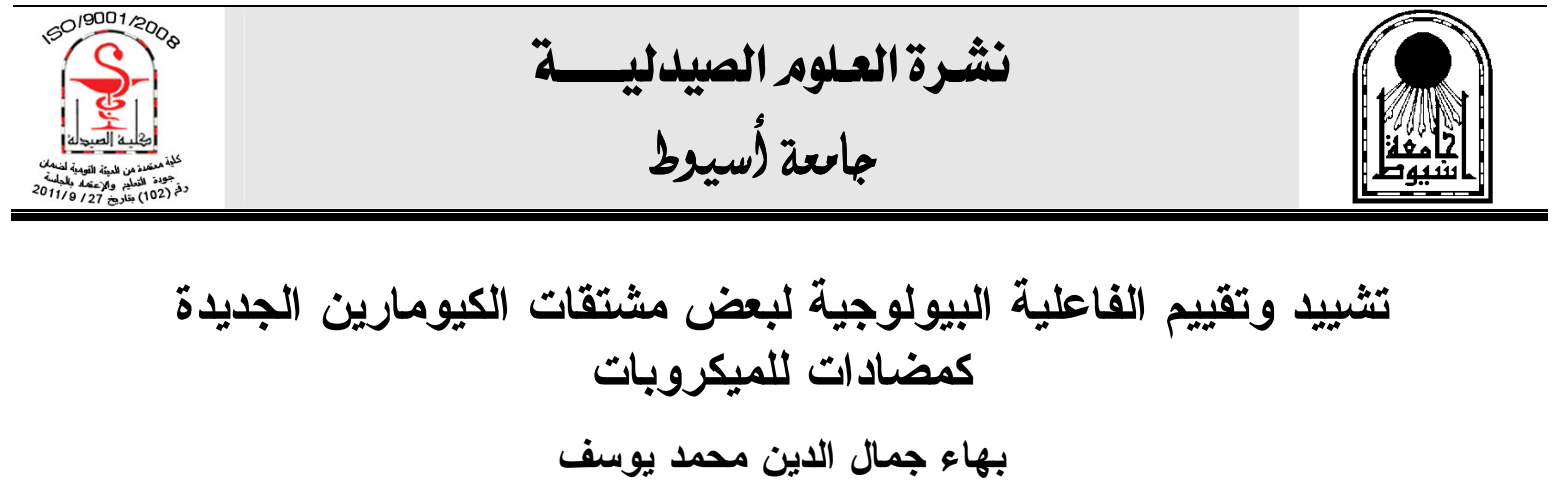

قسم الكيمياء العضوية الصيدلية ، كلية الصيدلة ، جامعة أسيوط ، أسيوط Y Y Y Y ، مصر 


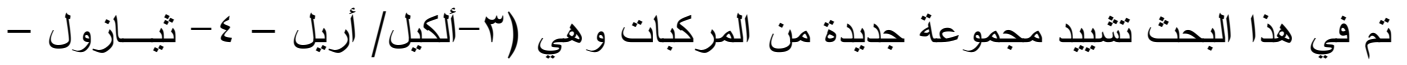

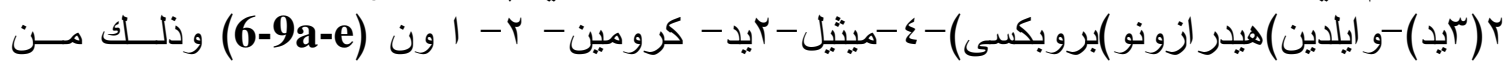

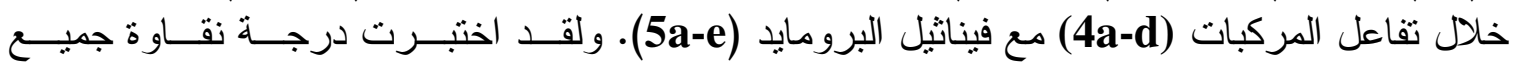

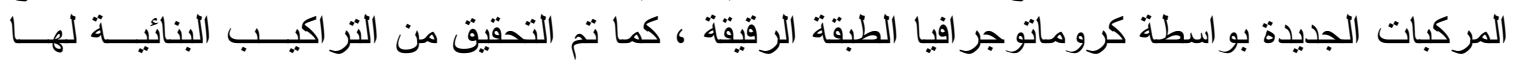

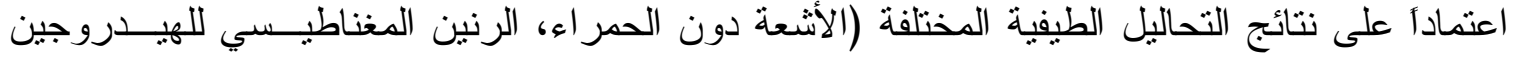
ومطياف الكتلة) بالإضافة إلى التحليل الكمي الدقيق لعناصر تلكالك المركبات.

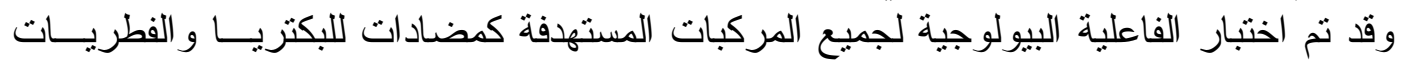

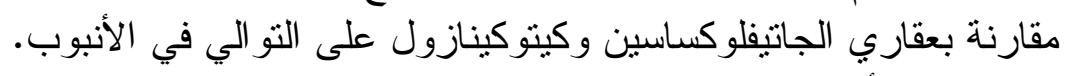

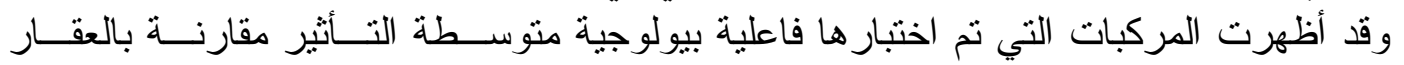

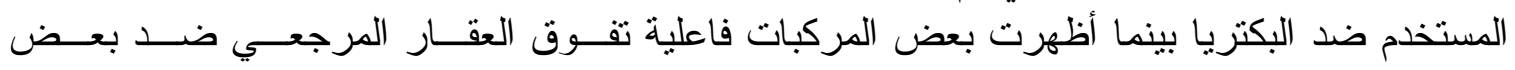

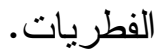

